\title{
Energy efficiency of flooded roofs: the University of Alicante Museum
}

\author{
V. Echarri Iribarren, A. Espinosa Fernández \& \\ A. Galiano Garrigós \\ "Technology and Sustainability in Architecture" Research Group, \\ University of Alicante, Spain
}

\begin{abstract}
Inverted flat roofs were adopted as a common construction solution throughout the Modern Movement. They require greater protection of the waterproofing layer and sufficient thermal insulation. Depending on the climate conditions, a thicker or thinner thermal layer is installed and energy saving in keeping with the climatic conditions, regulations or national or regional energy policies is obtained. However, the common construction systems tend to be focused on minimising the construction costs of each project, using thermal insulation layers of extruded polystyrene, a modified bitumen waterproofing layer and a finishing layer of $5 \mathrm{~cm}$ of gravel. In the case of trafficable roofs, this layer is substituted with ceramic or hydraulic concrete paving. These solutions have given rise to an enormous reduction in the thermal mass of the roof layers located above the isolation layer and consequently, a lack of thermal inertia with which to cushion the effect of the thermal wave of the outdoor environment produced in the indoor climate of the building. Roofs flooded with water in climatologies which allow their application generate significant thermal inertia depending on the depth of the water. They reduce the amplitude of the thermal wave produced in the inside temperature of the buildings by the external thermal variations, generating a considerable increase in comfort and a reduction in energy consumption. This paper outlines the research carried out in the Alicante University Museum. The whole building and its flooded roof have been monitored over a full year cycle and data has been obtained regarding the dry interior temperatures of each layer of the walls, outdoor temperatures and solar radiation, relative humidities, etc. Through the use of simulation tools, comparative results of this roof with respect
\end{abstract}


to inverted flat roofs have been obtained, such as the decrement factor and the heat wave.

Keywords: flooded roofs, thermal inertia, energy efficiency, thermal insulation.

\section{Introduction}

The rising population and technological progress have led to the development of new comfort needs amongst inhabitants. Consequently, increasing power demands have become difficult to meet, when using conventional sources. Recent studies and approaches acknowledge the need to reduce energy consumption and gas emissions into the environment, more precisely in the area of building construction, which is responsible for $17 \%$ of final energy consumption values in cities [1]. The traditional building construction systems guarantee the comfort condition in buildings at the expense of excessive energy consumptions in heating and/or cooling, which is detrimental to the environmental aspects promoted by European Union Energy Efficiency Directives [2].

It is believed that the energy that contaminates the least is energy that is not generated; for this reason, measures need to be implemented to ensure that this principle is followed. Energy consumption and demand is variable over time and depends on climate conditions, type of built space, thermal characteristics and usage. However, to this must also be added the influence of construction elements' thermal inertia [3], the speed with which changes in environmental conditions affect indoor ambient conditions, and the space's energy consumption and demand [4].

The first step to be taken in this monitoring process is to carry out research [5]. Once the real thermal behaviour is determined, it will be possible to calculate and evaluate the dynamic thermal characteristics of a component subject to variable environmental conditions over time [6]. Under the scope of these research conditions, the object of analysis and comparison is the thermal inertia contribution of two existing roofs to the thermal behaviour of the two spaces [7]. Two types of roofs are used as reference: a walkable inverted flatroof, very common in today's building construction nation-wide [8] and a flooded roof.

\section{Description of the roofs under analysis}

\subsection{Walkable inverted flat-roof}

The walkable inverted flat-roof, forms part of the thermal envelope of a residential block, between party walls, situated in the Alicante town centre. More precisely, the research concentrates on the thermal influence of the roof within the living area covered by said roof: main room of attic D of the residential block. This residential block was not occupied the year the research was carried out. Since the building was not inhabited, the air-conditioning system installed was not operative, therefore this did not affect the data gathered. The windows 
were fitted with roller blinds with aluminium slats. In the south facing windows the blinds were partially rolled down, since installation, i.e. practically throughout the entire data gathering process. The north facing windows were not protected by blinds. Table 1 details the construction characteristics of the roof.

Table 1: Constructional features of the housing roof.

\begin{tabular}{|c|c|c|}
\hline Horizontal construction and upflow & \multirow{2}{*}{$\begin{array}{c}\text { Thickness } \\
(\mathrm{m})\end{array}$} & \multirow[t]{2}{*}{ EXT } \\
\hline Outside environment & & \\
\hline $1 \quad$ Paving file & 0,015 & \multirow{2}{*}{$==-=-=-==-=-0==$} \\
\hline 2 Mortar bed & 0,015 & \\
\hline 3 Membrane: Non-woven geotextile thermosol & 0,001 & \\
\hline $4 \quad$ Thermal insulation: XPS $[0.032 \mathrm{~W} /[\mathrm{mK}]]$ & 0,030 & \\
\hline 5 Water proofing membrane: LBM-30-FV, LBM-40-FP & 0,006 & $\mid$ \\
\hline $6 \quad$ Mortar bed & 0,015 & 8 \\
\hline $7 \quad$ Aerated concrete & 0,070 & \\
\hline 8 Rainforced concrete & 0,300 & | \\
\hline 9 Trim and plaster & 0,015 & \multirow[b]{2}{*}{ INT } \\
\hline Inside environment & & \\
\hline
\end{tabular}

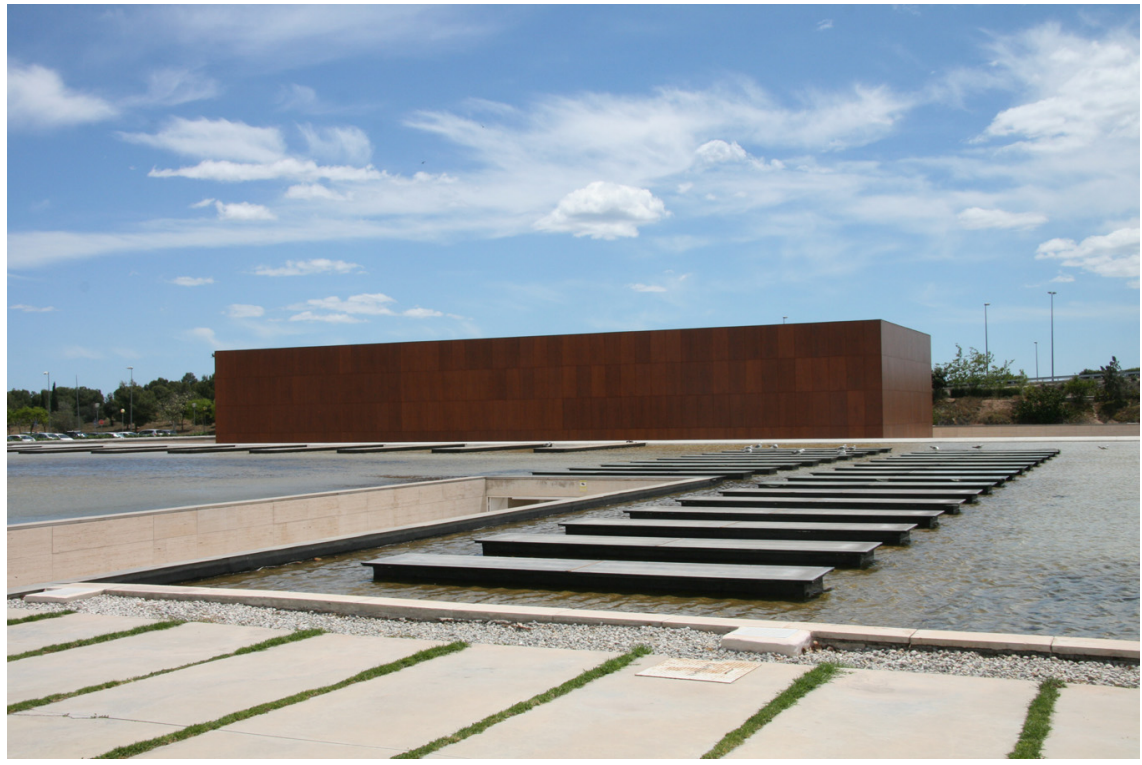

Figure 1: Typical view of the Museum MUA - current state.

\subsection{Flooded roof of the MUA}

The flooded roof forms part of the thermal envelope of a tertiary building, the Museum of the University of Alicante [9], located in San Vicente del Raspeig, a municipal town near Alicante. More precisely, this research concentrates on the thermal influence of flooded roofs on the living space covered by said roofs: area 
of the Museum's management offices. The room covered by the flooded-roof being analyzed, forms part of a space that was acclimatized throughout the entire monitoring period. Moreover, the windows of the southern facade are protected by opaque roll-up curtains. These curtains are always rolled-down, preventing the inflow of light into the exhibition room. Throughout the year under review, the thickness of the sheet of water on the flooded roof, varied between 10 and $20 \mathrm{~cm}$. This behaviour is due to water volume loss and gain, arising as a result of evaporation processes and rainfalls. The roof does not incorporate an auto-fill system to maintain roof's water level constant. Table 2 details the construction characteristics.

Table 2: Constructional features of the MUA roof.

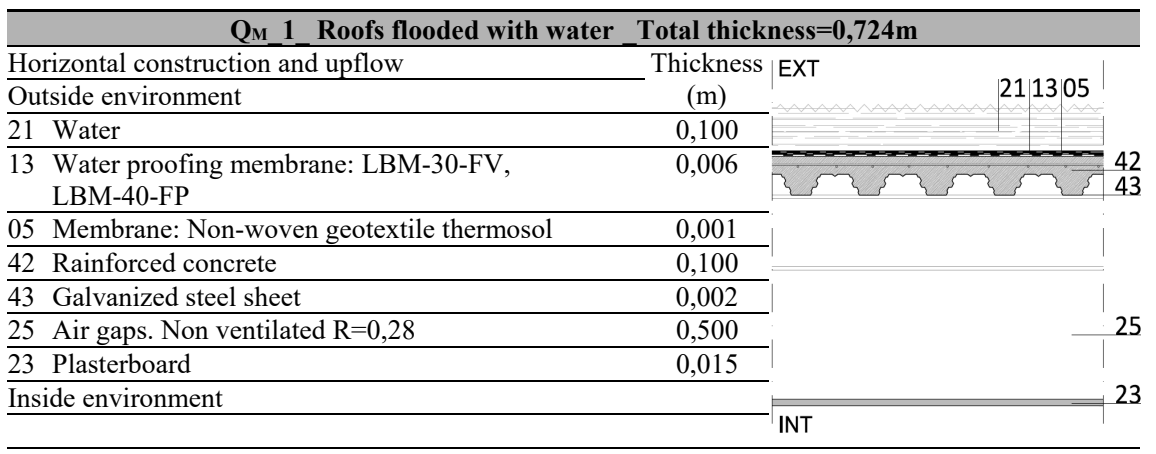

\subsection{The dynamic thermal characteristics analyzed}

One way of having energy available in buildings, when required, is through energy accumulation. This way it will be possible to reduce temperature drops by distributing energy throughout various consumption spans. The UNE EN ISO 13786 "Thermal performance of building products and components. Dynamic Thermal Characteristics. Calculation Methods", describes how to evaluate the manner in which building elements contribute towards the energy saving and consumption in buildings. The dynamic thermal characteristics of a building component describe its thermal behaviour when subject to variable environment conditions over time, such as heat or temperature, on its facades. The properties to be considered are thermal admittances and dynamic heat transfer, for the periodic variations described. Thermal admittance associated to heat flow due to temperature changes. Dynamic heat transfer properties combine the physical variables on one face of the component with the properties of the other building faces. Thermal characteristics may be used in both specific products and constructive sections composed of layers of materials [10].

This research centres on buffering factor dynamic components and the time lag of the thermal wave. These parameters were obtained from monitoring process data gathered during each of the previously mentioned construction sections. 


\subsubsection{Effusivity and buffering factor}

This value represents the temperature ranges of indoor and outdoor spaces and whose value depends on the thickness and effusivity of each material that forms the construction section. The buffering of a construction section is not a cumulative buffering process of each type of material. The buffering of each layer is applied to the energy released by each prior material layer [11]. For each of the roofs analysed, the buffering factor was analysed. The process carried out was as follows:

1. The thermal buffering value of each section was calculated for a 24-hour cycle, following the matrix method described in the UNE ISO 13786 standard [12].

2. The data obtained during the monitoring process is used to calculate the thermal buffering of each roof section. A maximum and minimum indoor and outdoor ambient temperature value is selected for each day of the year being monitored. The buffering factor, per day, is calculated using the formula in Figure 2.

3. The values provided by the standard are graphed and compared against the experimental values.

\subsubsection{Diffusivity and time lag}

Another thermal characteristic analysed was thermal diffusivity: capacity of a material to transfer temperature changes. This thermal time lag is used to analyze heterogeneous construction sections' capacity to attenuate temperature ranges. This value defines the time that elapses between ambient temperature changes and its appearance on the opposite face of a construction component submitted to a transitional heat calculation method. The time lag process is added to the partial time lags of each of the layers [11].

The time lag factor was analysed for each roof under analysis.

1. The thermal time lag value of each section was calculated, for each 24-hour cycle, following the matrix method described in the UNE ISO 13786 standard.

2. The data obtained during the monitoring process is used to calculate the thermal time lag for each roof section. The maximum and minimum values for internal and external surface temperatures are calculated for each day of the year being monitored.

3. The values provided by the standard are graphed and compared against the experimental values.

\section{Development of the experimental analysis (monitoring)}

\subsection{Defining the monitoring equipment}

The monitoring process consisted in gathering climate data like temperature, humidity and solar radiation and characteristic data of the construction sections during a full one-year cycle, on each case, every thirty minutes. To complete the analysis of climate data, climate data from other sources was also used: 
- National Institute of Meteorology (AEMET): EST_8025 and EST_8019 weather stations;

- University of Alicante's Climate Lab.

The following sensors and data recorders were used: Datalogger with incorporated sensor for measurement and gathering of environment temperature and relative humidity data (Sensor Chip: SHT21 generation chip 4C CMOSens); type $\mathrm{K}$ thermocouple sensor of the surface formed by a $13 \mathrm{~mm} \times 25 \mathrm{~mm}$ metal surface and a intertwined stainless steel cable; type $\mathrm{K}$ thermocouple formed by a $100 \mathrm{~mm}$ stainless steel probe and optic fibre twisted cable; Sensor, CMP3 pyranometer model, for overall solar radiation measurement. Tables 3 and 4 show the location of the sensors on the layers of the roofs under observation. In the case of the residential building, sensors were installed during the construction phase of the roof. In the MUA the layers were accessible due to the revamping done.

Table 3: Location of the sensors of the residential building's roof.

\begin{tabular}{|c|c|c|c|}
\hline \multicolumn{4}{|c|}{$\mathrm{Q}_{\mathrm{R}_{-} 1}$ Inverted flat roofs Total thickness $=0,467 \mathrm{~m}$} \\
\hline Horizontal construction and upflow & Thickness & & \\
\hline Outside environment & (m) & I EXT & \\
\hline $1 \quad$ Paving file & 0,015 & & \\
\hline $2 \quad$ Mortar bed & 0,015 & $=8$ & $=$ \\
\hline $3 \quad$ Membrane: Non-wovwn geotextile thermosol & 0,001 & $O_{1} Q_{a 3}$ & $\bar{a}_{82}$ \\
\hline $4 \quad$ Thermal insulation: XPS $[0.032 \mathrm{~W} /[\mathrm{mK}]]$ & 0,030 & & \\
\hline $\begin{array}{l}5 \text { Water proofing membrane: LBM-30-FV, } \\
\text { LBM-40-FP }\end{array}$ & 0,006 & & Q \\
\hline $6 \quad$ Mortar bed & 0,015 & & \\
\hline $7 \quad$ Aerated concrete & 0,070 & & \\
\hline 8 Rainforced concrete & 0,300 & & \\
\hline 9 Trim and plaster & 0,015 & & \\
\hline Inside environment & & INT & $\mid \begin{array}{l}a_{80} \\
a_{\text {zim }}\end{array}$ \\
\hline
\end{tabular}

Table 4: Location of the sensors of the MUA's roof.

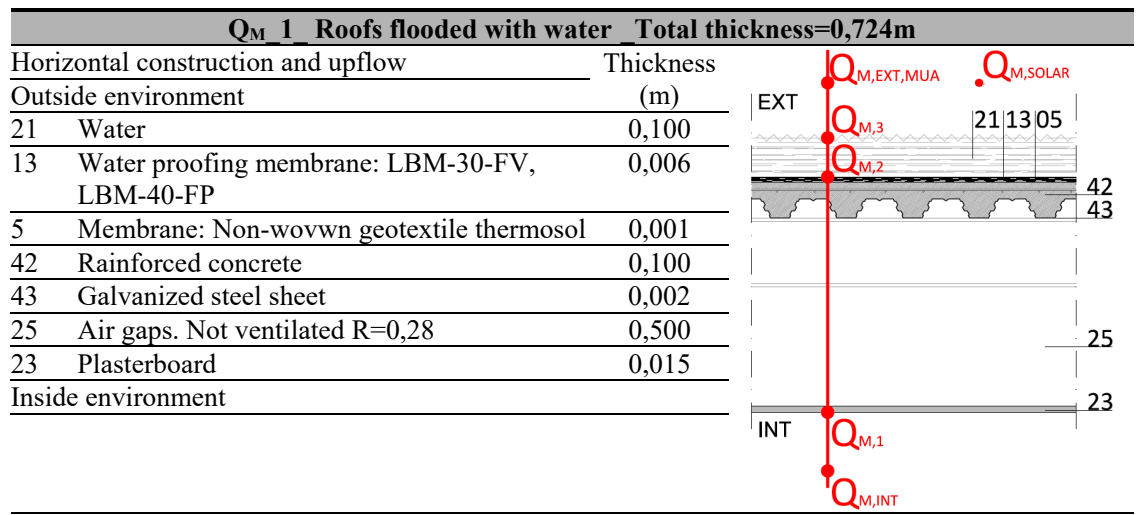




\section{Results}

\subsection{Results of the monitoring process}

For each seasonal period was selected the day with the widest temperature range, i.e. with the highest outdoor ambient temperature change:

A. Walkable inverted flat-roof:

- Spring: 12 April 2014, from 00:00:00 until 24:00:00.

- Summer: 16 July 2014, from 00:00:00 until 24:00:00.

- Autumn: 21 October 2014, from 00:00:00 until 24:00:00.

- Winter: 10 January 2015, from 00:00:00 until 24:00:00.

B. Flooded roof:

- Spring: 21 May 2014, from 00:00:00 until 24:00:00.

- Summer: 11 September 2014, from 00:00:00 until 24:00:00.

- Autumn: 23 October 2014, from 00:00:00 until 24:00:00.

- Winter: 29 January 2015, from 00:00:00 until 24:00:00.

In Figures 2 and 3 are represented the values of interior and exterior ambient temperatures, solar radiation and surface temperatures of both sections. The internal surface temperatures, of materials that make up the section of the walkable inverted flat-roof, are also represented in graph format. To reference the thermal comfort [13], two lines are graphed to represent the maximum and minimum indoor ambient temperature values obtained from the comfort conditions following regulations for thermal installations in buildings (in Spanish, RITE) [14].

The temperature on the exterior surface of the roof, finished-pavement (Figure 2), is higher than the ambient temperature. The outdoor air temperature values obtained in spring was $38.16 \%$, in summer $37.28 \%$, in autumn $26.28 \%$ and in winter $24.26 \%$ below the temperature of the pavement surface, related to the impact of solar radiation. In the construction section different thermal zones arise due to the thermal capacity and inertia of the materials:

- The area of the section ranging from the indoor ambient to the thermal isolation of the layer (excluded). This is due to the thermal mass accumulated by the materials in the section.

- The area of the section ranging from the outdoor ambient to the thermal isolation of the layer (excluded). The thermal isolation layer, absorbers outdoor temperature variations, allowing the section's internal mass to buffer indoor ambient temperature changes.

The residential incorporates a thermal conditioning system, but this system was not operative during the analysis period. Notwithstanding this circumstance, the ambient temperature was uniform but, as indicated in the graphs, outdoor the thermal comfort parameters. 

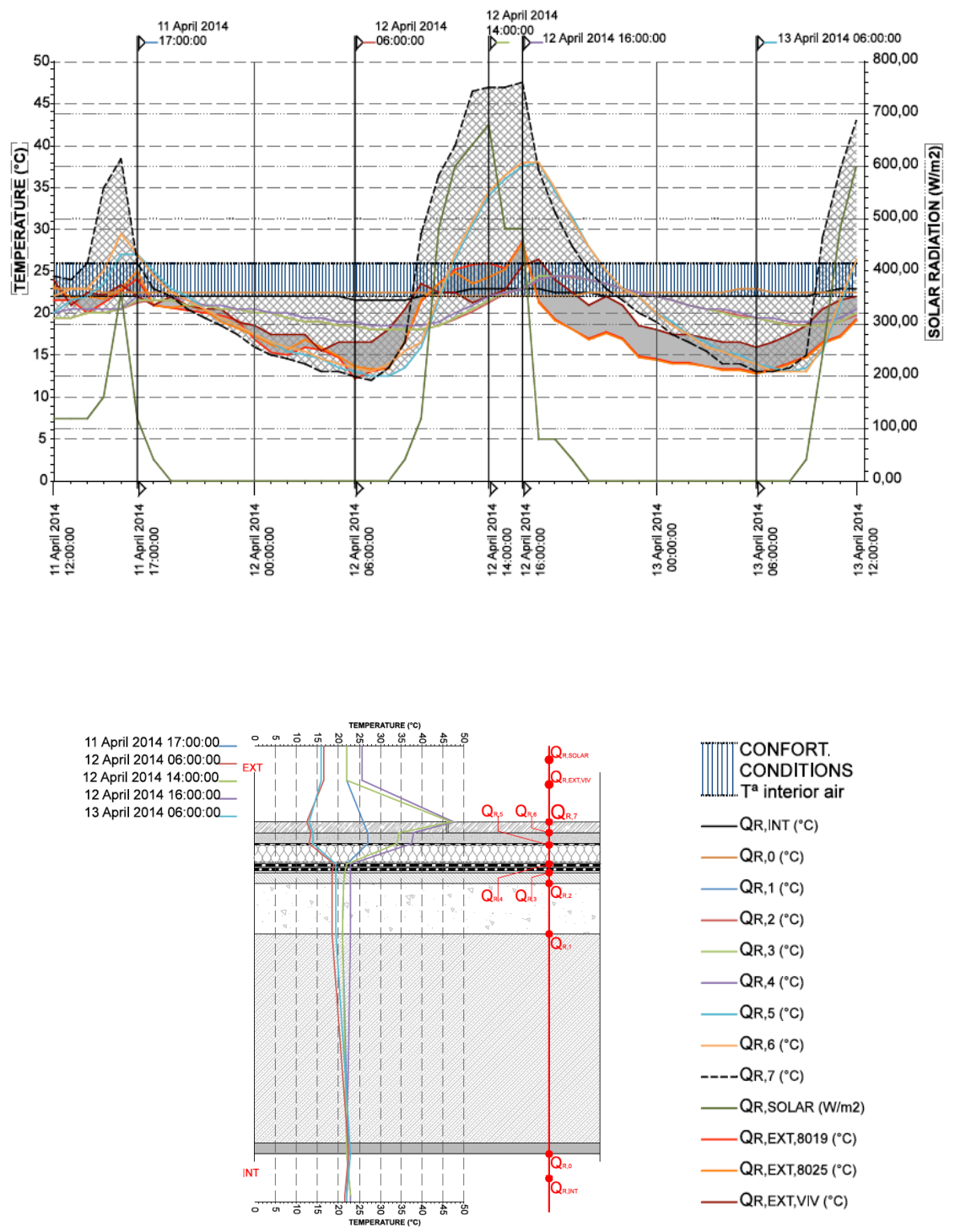

Figure 2: Solar radiation and surface and environment temp - inverted flat roof. 


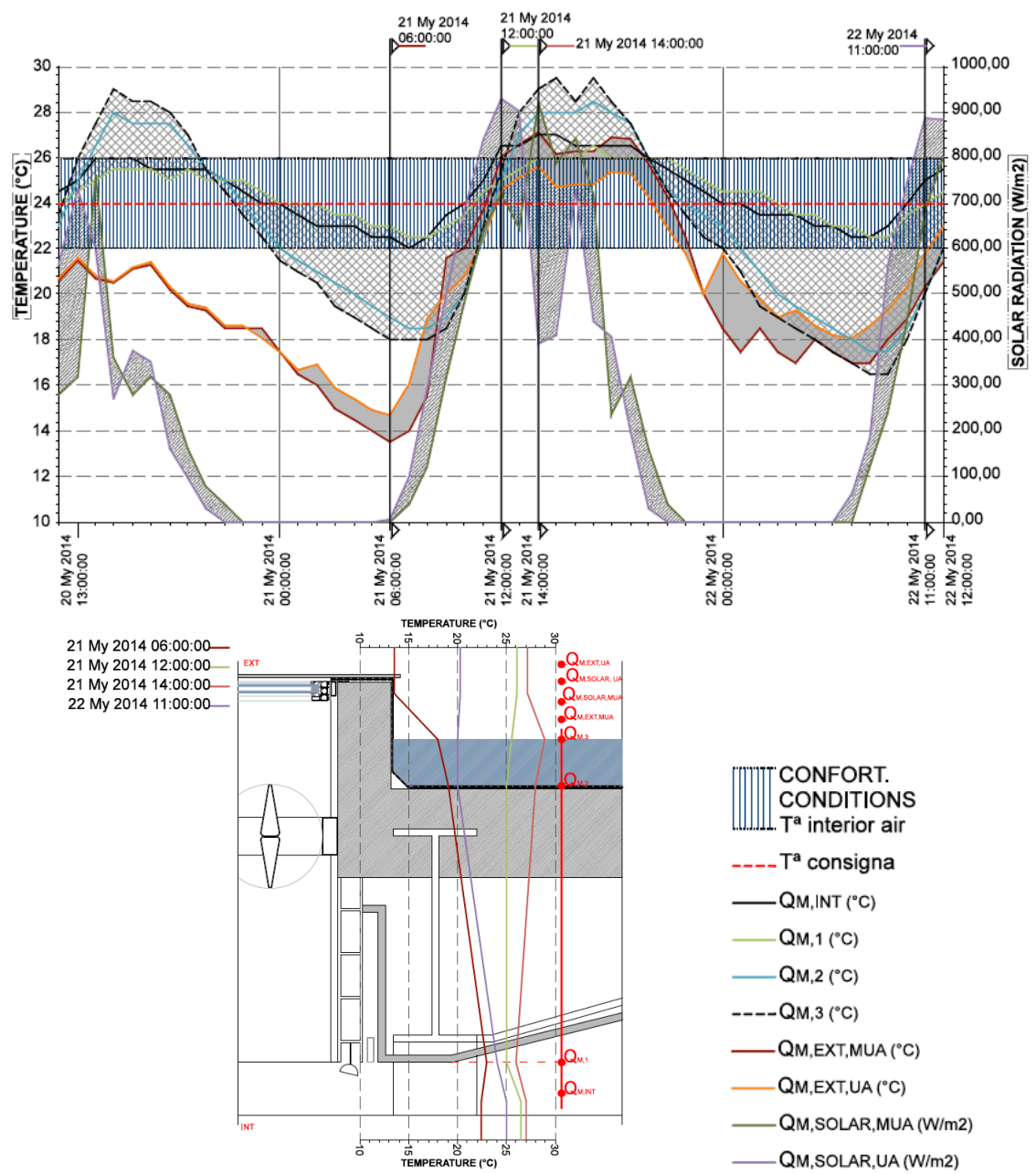

Figure 3: Solar radiation and surface and environment temp - flooded roof.

In the case of the walkable flooded roof, the exterior roof (Figure 3), surface temperature, sheet of water, varies in relation to the exterior ambient temperature, but in ranges different to those of the dwelling. This area, where the ambient temperature increases before it reaches the water surface, is represented in the graphs. Based on data obtained, the exterior air temperature is $38.60 \%$ in spring, $25.1 \%$ in summer, 18.205 in autumn and 18.80 in winter. But, always below the temperature of the water sheet surface. It is important to highlight the non-existence of two different thermal areas. This is due to the fact that the construction section does incorporate thermal isolation. The room incorporates a thermal conditioning system, but this system was not operative 
during the analysis period. Consequently indoor temperatures fluctuate between the programmed set temperatures, in majority of the situations, not meeting comfort parameters. Throughout the year of the analysis the thickness of the water sheet varied between 10 and $20 \mathrm{~cm}$. The roof does not incorporate an autofill system to control the roof's water level and to maintain it constant.

\subsection{Buffering factor}

Figures 4 and 5 were drafted based on the resulting thermal buffering data, obtained following standard requisites and using the thermal values recorded throughout the roof monitoring process.

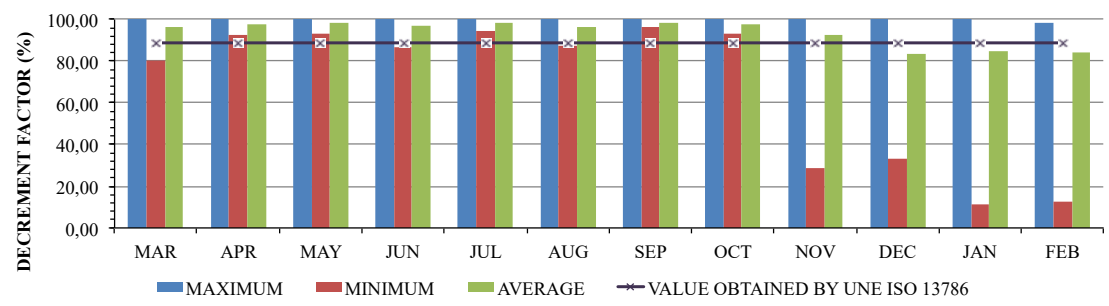

Figure 4: Decrement factor (\%) - inverted flat roof.

In the case of the walkable inverted flat-roof (Figure 4), the maximum values, $100 \%$, correspond to moments during which the indoor air temperature did not change. The minimum values vary, to a great extent, between $80 \%$ and $96 \%$. These were the values obtained during the spring, summer and autumn seasons. From November to January, the minimum buffering values drop to between $11 \%$ and $29 \%$. Such low buffering values relate to periods during which the buffer range of outdoor temperature is higher than the thermal range of indoor temperatures. Outdoor temperatures fluctuate more than indoor temperatures.

If the analysis concentrates on the average annual buffering value, obtained from the temperature values recorded during the monitoring process, for a 24hour cycle, the annual average value of thermal wave buffering is $6.2 \%$, i.e. $93.81 \%$ of the heat transfer does not occur in the interior. The range of the internal wave is reduced by $93.81 \%$ in relation to the range of the external wave, and for this reason indoor temperatures remain constant. According to the UNE ISO 13786 , for a 24 -hour cycle, the buffering of the thermal wave is $11.2 \%$, i.e., $88.82 \%$ of the heat transfer does not take place indoors. The range of the internal wave is reduced by $88.82 \%$ in relation to the range of the external wave, and for this reason indoor temperatures remain almost linear.

In the case of the flooded roof (Figure 5), the average annual buffering value, obtained during the monitoring process for a period of 24 hours, is $28.6 \%$, i.e., $71.40 \%$ of the heat transfer, does not pass indoors. The range of the internal wave is reduced, in relation to the range of the external wave by $71.40 \%$. According to the UNE ISO 13786, for a 24-hour cycle, the buffering of the thermal wave is $7.9 \%$, i.e. $92.1 \%$, as was the case with the previously mentioned roof. 


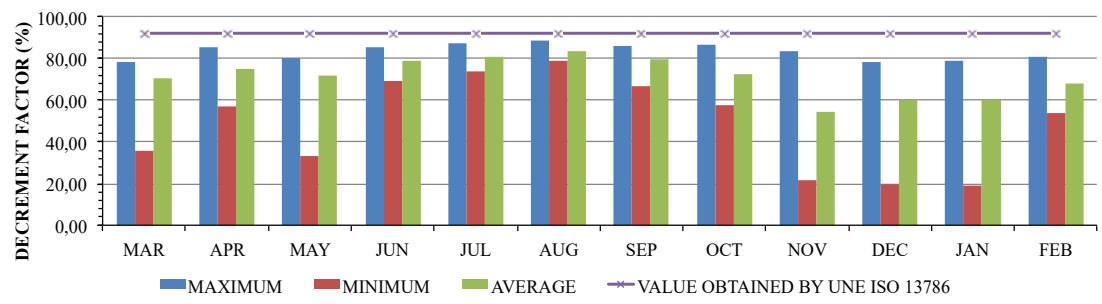

Figure 5: Decrement factor (\%) - flooded roof of the MUA.

\subsection{Time lag of thermal waves}

In Figures 6 and 7, the maximum, minimum and average values of the thermal time lag for each month are represented, obtained based on temperature data recorded during the monitoring process. In the same graph is included the buffering constant value as indicated in the UNE EN ISO 13786 standard.

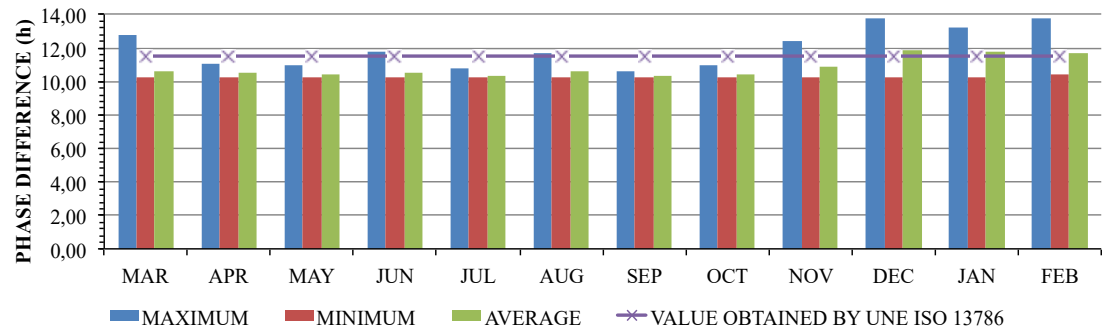

Figure 6: Phase difference of heat wave (hours) - inverted flat roof.

In the case of the walkable roof (Figure 6), the annual average value of the time lag of the thermal wave, based on the values obtained during the monitoring process, for a period of 24 hours, is $10.832 \mathrm{hrs}$, i.e., it takes $10.832 \mathrm{hrs}$ for the heat to pass through the roof. The time lag value of the thermal wave, obtained according to the UNE ISO 13786 standard, is $11.492 \mathrm{hrs}$, for the entire section of the roof. That is, it takes $11.492 \mathrm{hrs}$ for the heat to pass through the roof.

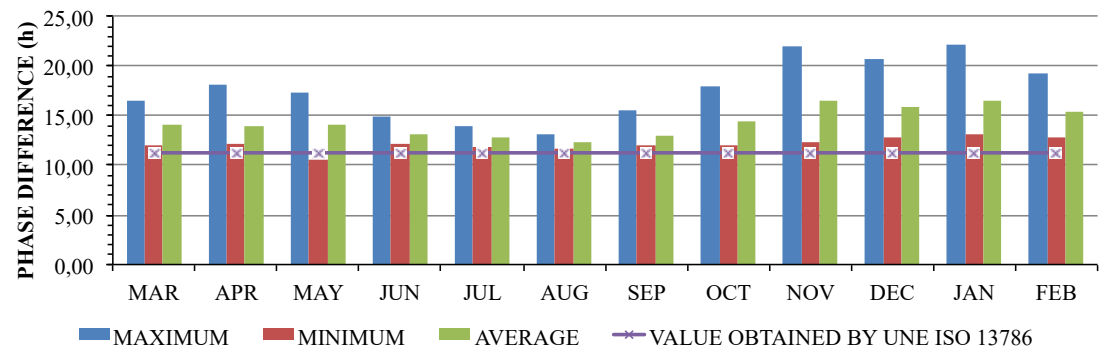

Figure 7: $\quad$ Phase difference of heat wave (hours) - flooded roof of the MUA. 
Likewise, for the flooded roof (Figure 7), the annual average value of the time lag of the thermal wave, for a period of 24 hours, is $14.36 \mathrm{hrs}$, i.e., it takes 14.36 hrs for the heat to pass through the roof. The time lag value of the thermal wave is $11.252 \mathrm{hrs}$, for the entire section of the roof.

\section{Conclusions}

When studying the energetic behaviour of an architectural space, it is indispensable to monitor the element being analysed. During the winter, when the flooded roof was monitored, it was difficult to analyse the recovery of thermal inertia, because of the fact that air-conditioning systems were also being used. In the case of the inverted flat-roof, it was observed that indoor air temperature tendencies are almost linear; temperature does not vary at the same pace as the outdoor air temperature does. For the exhibition space, where the flooded roof without thermal isolation is situated, the tendency of indoor ambient temperatures is not linear. Throughout the day, minimum temperature values were recorded during the early hours of the morning and at midday maximum values were recorded.

In what concerns thermal buffering, in the analysis of both roofs, the inverted flat roof applied over an interior ambient without operating air-conditioning system, as was the case with the flooded roof of the MUA, which was permanently acclimatized, its thermal behaviour is as indicated in the UNE EN ISO 13786 standard is the real behaviour, annual average value, obtained whilst monitoring of the construction section. In the case of the flooded roof, because of the air-conditioning system installed the thermal buffering values obtained throughout the year were very low. The room's thermal air-conditioning system maintains indoor temperatures within the set values; this affects the internal thermal range which is calculated based on indoor and outdoor temperature range ratios. Consequently, the air-conditioning system affects indoor ambient temperatures and the buffering values of the wave change, and therefore do not represent a real behaviour. If we compare the thermal buffering of the two roofs based on standard values, the $92.10 \%$ thermal wave buffering obtained for the flooded roof is higher than the $88.82 \%$ obtained for the walkable inverted flatroof.

In what concerns the time lag of the thermal wave, in the case of the inverted flat roof, the theoretical behaviour is equal to the real-life behaviour of the construction section. On the contrary, the analysis of data obtained for the flooded roof shows that the theoretical behaviour is slightly different to real-life behaviour of the construction section. Since this space is acclimatized throughout the entire annual period recorded, the values of the indoor temperatures are conditioned by the air-conditioning system and programmed set temperatures. Therefore, if we concentrate on the comparative of the time lag of the thermal wave for the two roofs, based on standard values, there is a time lag of 11.25 hrs between outdoor and indoor maximum temperature values obtained for the flooded roof, whilst for the walkable inverted flat roof the time lag is $11.49 \mathrm{hrs}$. 


\section{References}

[1] http://www.idae.es/index.php/mod.pags/mem.detalle/relcategoria.1154/id. 397/relmenu.11

[2] Directive 2010/31/EU of the European Parliament and of the Council of 19th May 2010 on the energy performance of buildings.

[3] Domínguez, M.; Santamaría, S. "Importancia de la inercia térmica de los cerramientos", en Conarquitectura: colectiva, centro cultural, polideportivo, viv.unifamiliar, $\mathrm{n}^{\circ}$ 03, 2001, pp. 49-56.

[4] Basic Document Energy Saving, section HE 1, Limitation of Energy Demand, Spanish Technical Building Code regulations.

[5] León, A.; Muñoz, S.; León, J.; Bustamante, P. "Monitorización de variables medioambientales y energéticas en la construcción de viviendas protegidas: Edificio Cros-Pirotecnia en Savilla", en Informes de la Construcción, vol.62, $\mathrm{n}^{\circ}$ 519, 2010, pp. 67-82.

[6] UNE EN ISO 13786:2011. Thermal performance of building products and components. Dynamic thermal characteristics. Calculation methods.

[7] Cabeza Prieto, A.; Sánchez-Guevara, C.; Camino Olea, M.S. "Estudio de la contribución de la inercia térmica al comportamiento térmico de edificios", en Libro de Actas, I Congreso Internacional sobre investigación en Construcción y Tecnología Arquitectónicas. Madrid, 2014, pp. 69-81.

[8] Fernández Madrid, Joaquín. "La cubierta plana”, en Téctónica Cubiertas (I) PLANAS, n 6, Madrid, 1999, pp. 12-27.

[9] Payá, Alfredo. "Museo universitario de Alicante", en El Croquis, n96/97, 1999, pp. 232-243.

[10] Wang, S.; Youming, C. "A simple procedure for calculating thermal response factors and conduction transfer functions of multilayer walls", en Applied Thermal Engineering, $\mathrm{n}^{\circ} 22,2002$, pp. 333-338.

[11] Bedoya, César; Neila, Javier. Técnicas arquitectónicas y constructivas de Acondicionamiento ambiental, Ediciones Munilla-Lería, Madrid, 1997.

[12] UNE EN ISO 13786 "Thermal performance of building products and components. Dynamic thermal characteristics. Calculation methods".

[13] Echarri V; Galiano-Garrigós; A; Pérez-Millán; M. I; González-Avilés; A. B. "Conditioning systems by radiant surfaces: comparative analysis of thermal ceramic panels versus the conventional systems in a museum", in WIT Transactions on Engineering Sciences. Vol. 83, 2014.

[14] Update version of Royal Decree 1027/2007, 20 of July, approves RITE: Reglamento de Instalaciones Térmicas en los Edificios, taking into account corrections and modifications made to the same from its publication in the B.O.E. 29 August 2007. 